\title{
A constituição da representação pela criança com síndrome de Down
}

\author{
Fabíola Custódio Flabiano ${ }^{1}$
}

Flabiano FC. A constituição da representação pela criança com síndrome de Down [tese]. São Paulo: Faculdade de Medicina, Universidade de São Paulo; 2010.

De acordo com a Epistemologia Genética, a linguagem possui relação direta com a construção do conhecimento. Tal relação é claramente observada a partir da constituição da representação, que permite ao indivíduo expressar seu pensamento por meio da linguagem oral. O objetivo da presente tese foi caracterizar o processo de constituição da representação pela criança com síndrome de Down (SD), investigando também a relação entre o uso de gestos e a emergência da linguagem oral. Dez crianças com SD e 15 crianças com desenvolvimento típico (DT) foram submetidas a sessões mensais de observação do desenvolvimento cognitivo e da linguagem expressiva, de acordo com o Protocolo para Observação do Desenvolvimento Cognitivo e da Linguagem Expressiva - versão revisada (PODCLE-r). As sessões foram realizadas durante o período de dez meses, a partir da sessão em que os sujeitos estavam localizados no início da quarta fase do período sensoriomotor. Todas as sessões foram registradas em vídeo e transcritas em protocolo específico. Para melhor discussão dos dados, a pesquisa foi dividida em dois estudos. O objetivo do Estudo I foi caracterizar o processo percorrido pelas crianças com SD até chegarem à condição de representação, em comparação a crianças com DT. No Estudo II, a partir de uma análise mais detalhada desse processo, buscou-se investigar a relação entre o uso de gestos e a emergência da linguagem oral em crianças com SD em comparação a crianças com DT, equiparadas pela idade cognitiva. Os resultados revelaram que as crianças com SD apresentaram ritmo de desenvolvimento mais lento, tanto em relação ao desenvolvimento cognitivo quanto ao da linguagem expressiva. Além disso, foram observadas diferenças qualitativas entre os grupos em relação à diversidade de suas produções, com menor diversidade quanto maior a complexidade dos indicadores do desenvolvimento cognitivo e da linguagem expressiva, pelas crianças com SD. Essas crianças também apresentaram déficits mais significativos em relação à linguagem expressiva do que em relação ao desenvolvimento cognitivo, com dificuldades maiores no processo de transição das combinações de gesto e palavra para as combinações de duas palavras, especialmente em relação às combinações que envolviam somente elementos representativos. Esses achados sugerem que as crianças com SD, além de apresentarem atraso no desenvolvimento cognitivo e da linguagem expressiva, como relatado na literatura, podem apresentar dificuldades específicas no processo de desenvolvimento de ambas as áreas, as quais devem ser consideradas durante o processo terapêutico fonoaudiológico, de forma a favorecer sua maior efetividade.

Trabalho realizado no Programa de Ciências da Reabilitação da Faculdade de Medicina da Universidade de São Paulo - USP - São Paulo (SP), Brasil, para obtenção do título de Doutora em Comunicação Humana, sob orientação da Professor Dra. Suelly Cecília Olivan Limongi.

(1) Doutora, Pesquisadora do Laboratório de Investigação Fonoaudiológica em Síndromes e Alterações Sensório-Motoras da Faculdade de Medicina da Universidade de São Paulo - USP - São Paulo (SP), Brasil.

Endereço para correspondência: Fabíola Custódio Flabiano. R. Cipotânea, 51, Cidade Universitária, São Paulo (SP), Brasil, CEP: 05360-160. E-mail: fabiolaflabiano@yahoo.com.br 